\title{
Necropsy findings in a case of progressive vaccinia
}

\author{
F. J. PARADINAS AND EVE WILTSHAW \\ From Charing Cross Hospital Medical School and The Royal Marsden Hospital, London
}

SYNOPSIS A case of progressive vaccinia complicating chronic lymphocytic leukaemia is reported. At necropsy a vaccinial pneumonia, focal pancreatitis, and evidence of disseminated intravascular coagulation were found. Epithelial proliferation was noted in sweat glands, bronchi, and pancreatic ducts associated with lesions in these sites. The significance of these findings is discussed.

Progressive vaccinia is a rare but often lethal complication of smallpox vaccination. In this condition the lesion at the site of the inoculation fails to heal and becomes a progressively enlarging ulcer. New satellite vesicles often appear round this ulcer and secondary vesicles, thought to be due to haematogenous spread of the virus (Kempe, 1960), may arise in mucosal surfaces and distant areas of the skin. In some cases visceral lesions have been found at necropsy. In children the commonest underlying cause of this complication is congenital hypogammaglobulinaemia (Kempe, 1960) and in adults the immunological deficiency often associated with leukaemias or lymphomas (Dixon, 1970).

\section{Case Report}

A 69-year-old American woman had been found to have chronic lymphocytic leukaemia in 1963 but she was free of symptoms and no treatment was given. In 1965 she had been revaccinated against smallpox without any untoward reaction. In February 1969 and before a trip to Europe she had smallpox vaccination on the left upper arm. At this time she was taking $80 \mathrm{mg}$ of prednisone and $12 \mathrm{mg}$ of chlorambucil daily (Fig. 1).

On arrival in the UK she became febrile $\left(102^{\circ} \mathrm{F}\right)$ and weak. When examined in hospital she had multiple bruises and petechiae. On the left upper arm there was a $10 \times 8 \mathrm{~cm}$ reddened area with a raised border and a central black necrotic slough surrounded by a ring of vesicles (Fig. 2). One vesicle was present on the forehead. The left axillary and supraclavicular lymph nodes were enlarged and tender. The liver and spleen were palpable. Non-tender nodes were felt in the right axilla and both groins. No abnor-

Received for publication 6 July 1971. mality was found in the cardiovascular system (BP $120 / 75 \mathrm{~mm} \mathrm{Hg}$ ), respiratory system (the chest radiograph was clear), or central nervous system. The blood urea was $92 \mathrm{mg} / 100 \mathrm{ml}$; haemoglobin $13.2 \mathrm{~g} / 100 \mathrm{ml}$; WBC 23,000 per $\mathrm{cmm}$ with 19,000 lymphocytes per cmm; platelets 100,000 per $\mathrm{cmm}$; serum immunoglobulins; IgG $190 \mathrm{mg} / 100 \mathrm{ml}$, IgA $130 \mathrm{mg} / 100 \mathrm{ml}$, IgM $29 \mathrm{mg} / 100 \mathrm{ml}$. Vaccinia virus was isolated from the fluid of a vesicle in the arm.

\section{TREATMENT AND PROGRESS}

Chlorambucil was discontinued and the dose of prednisone was gradually reduced. Antivaccinial gammaglobulin and methisazone were given immediately. Because of the low absolute neutrophilic count (Fig. 1) reverse barrier nursing was used during the first 23 days in hospital.

In spite of this treatment new vesicles appeared in distant areas of the skin (Fig. 1) and the patient developed a generalized erythematous rash. Seventeen days after admission the erythema had subsided but new vesicles continued to appear and the haemoglobin fell to $10 \mathrm{~g} / 100 \mathrm{ml}$. By the 25 th day in hospital she was very weak and experienced sudden intermittent attacks of dyspnoea accompanied by falls in blood pressure. The blood urea was $46 \mathrm{mg} /$ $100 \mathrm{ml}$ and a chest radiograph showed scattered small shadows in both lung fields. Virus was again isolated from vesicles in the palate and right elbow. It was thought that the attacks of dyspnoea were due to pulmonary embolism and the patient was therefore given an intravenous infusion of heparin which was continued for two days. On the 35th day she collapsed, her blood urea rose to $134 \mathrm{mg} / 100 \mathrm{ml}$, and multiple vesicles appeared on the sacral region, right groin, and abdomen. She was treated with antibiotics, dextran, and a further heparin infusion, but she died next morning, 56 days after vaccination. 
Fig. 2 Appearance of the vaccination lesion on admission.

\section{Necropsy Findings}

The necropsy was performed 12 hours after death and permission was obtained for a limited internal examination only. As well as the skin lesions already described there was generalized skin oedema. Fresh ecchymoses and petechiae were present on the face, shoulders, and arms. The surface of the right lung was covered by fibrinous exudate. Scattered throughout the parenchyma of the lower lobes there were areas of grey consolidation up to $1.5 \mathrm{~cm}$ in diameter. The liver, spleen, and abdominal lymph nodes were enlarged. The pancreas was hard and showed foci of necrosis up to $0.3 \mathrm{~cm}$ in diameter. Other abdominal organs appeared normal.

\section{Histology}

The bone marrow and lymph nodes showed evidence of chronic lymphocytic leukaemia. The skin vesicles (Fig. 3) were intraepidermal and had the reticulating 


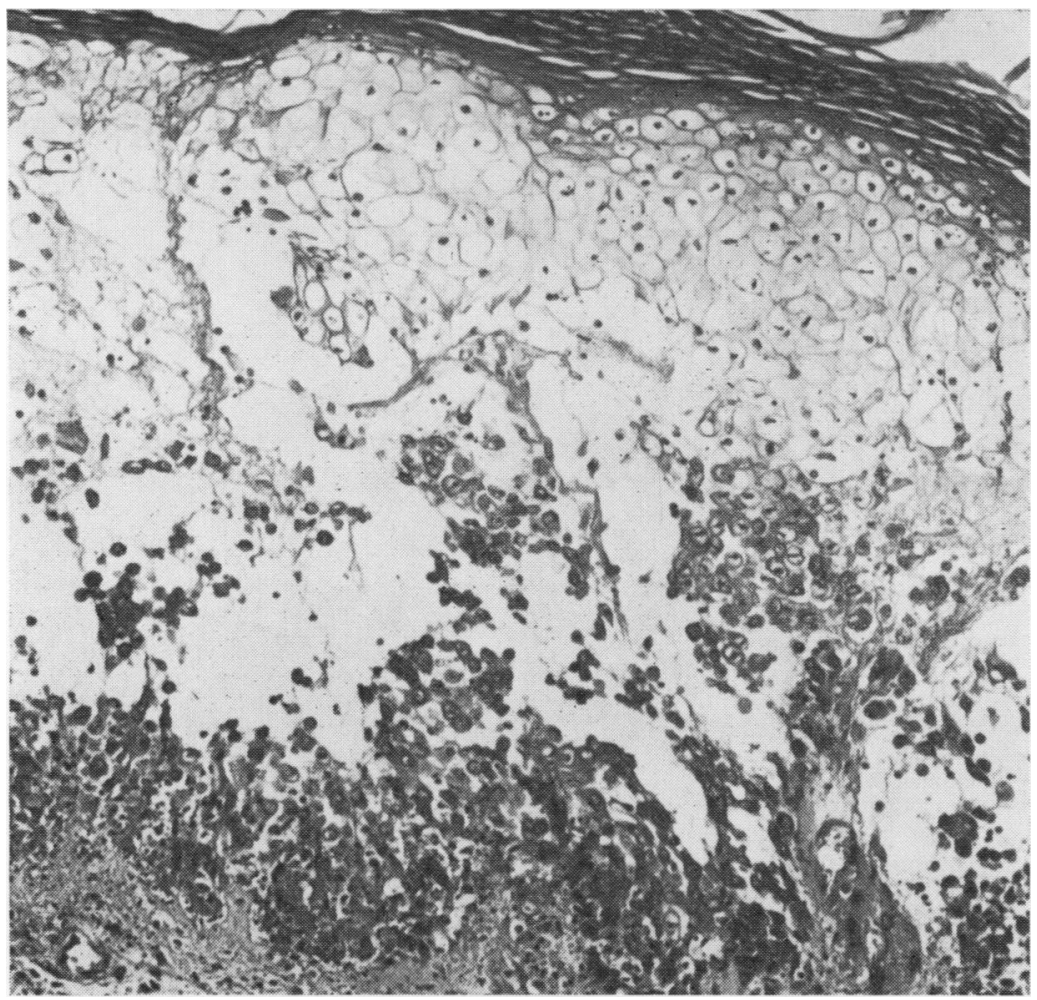

Fig. 3 Histology of a metastatic vesicle at necropsy. Reticulating degeneration is present in the superficial layers and ballooning degeneration in the deep layers of the epidermis. $H \& E \times 100$.

and ballooning types of degeneration typical of poxvirus lesions. Many epithelial cells contained round, circumscribed eosinophilic inclusions (Fig. 4). Ballooning degeneration was also present in sweat glands and hair follicles. In addition there was stratification of the epithelium in some of the sweat glands (Fig. 5). The areas of consolidation in the lung consisted of partially collapsed alveoli containing abundant fibrinous exudate, some red cells and a few neutrophils. In the middle the alveolar walls were necrotic and towards the periphery they were lined by swollen cells. Very occasionally one of these cells contained cytoplasmic eosinophilic inclusions. Several bronchi were lined by markedly hyperplastic epithelium (Fig. 6). Many small arterioles showed necrosis and oedema of the wall and the intima was coated by a layer of fibrin (Fig. 7). Alveolar capillaries, small arteries, and bronchial veins contained spheroidal aggregations of fibrin surrounded by one or several cells apparently derived from endothelium. In the pancreas there were areas of recent necrosis surrounded by a few neutrophils. In older lesions a few surviving acini were surrounded by many young fibroblasts, lymphocytes, and neutrophils. The pancreatic ducts in these areas showed numerous mitoses and in a few of them there was stratification of the epithelium (Fig. 8). A few small arterioles contained fibrin thrombi. Focal deposition of fibrin was prominent in the spleen. In the kidney several glomerular and intertubular capillaries and arterioles contained delicate fibrin thrombi (Fig. 9). In the liver there was congestion and focal fatty change. No necrosis was seen.

\section{Discussion}

The association of progressive vaccinia with various leukaemias and lymphomas is well documented (Dixon, 1970). It is noticeable that our patient was vaccinated on two different occasions after a diagnosis of chronic lymphocytic leukaemia had been made, and that at the time of the second vaccination she was receiving large doses of two powerful immunosuppressants.

\section{SKIN LESIONS}

In this case, the histological features of the vesicles correspond closely with those previously described in human progressive vaccinia (Dible and Gleave, 1934). Proliferation of the sweat gland epithelium 


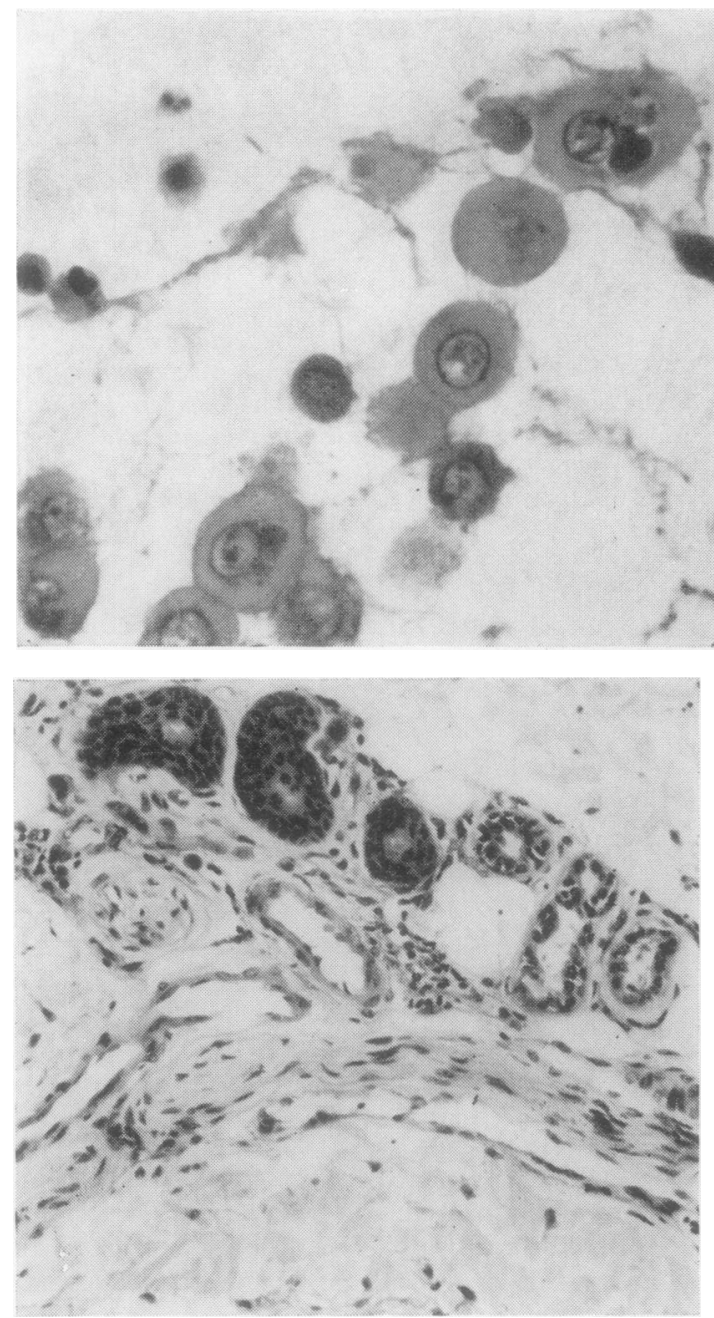

Fig. 5 .

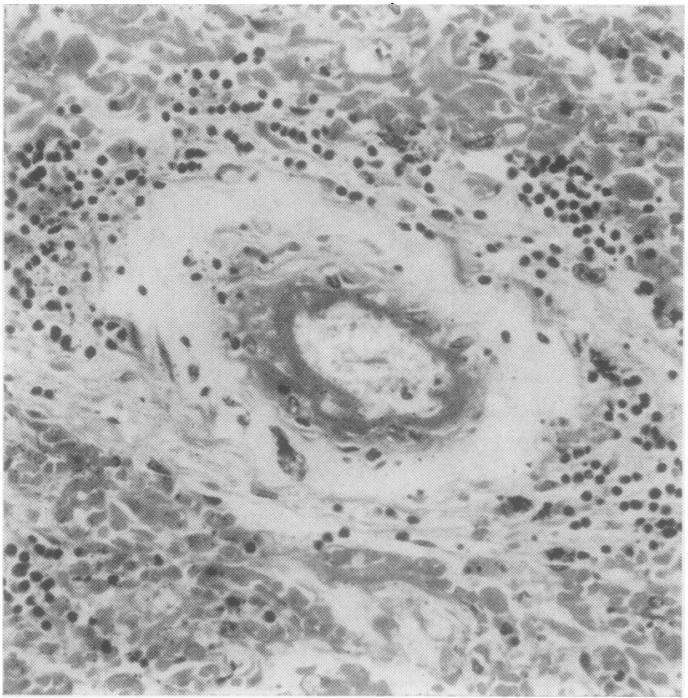

Fig. 7.

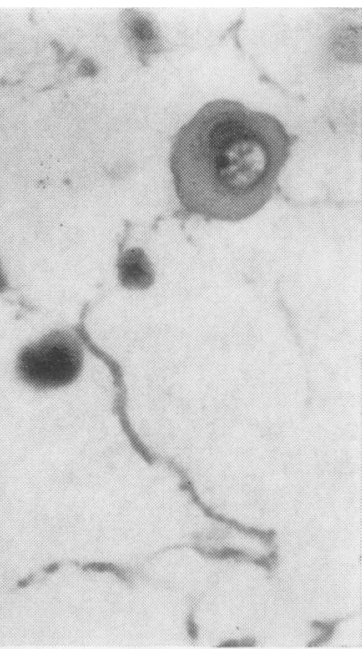

Fig. 4 Cytoplasmic inclusions in a skin lesion. $H \& E \times 600$.

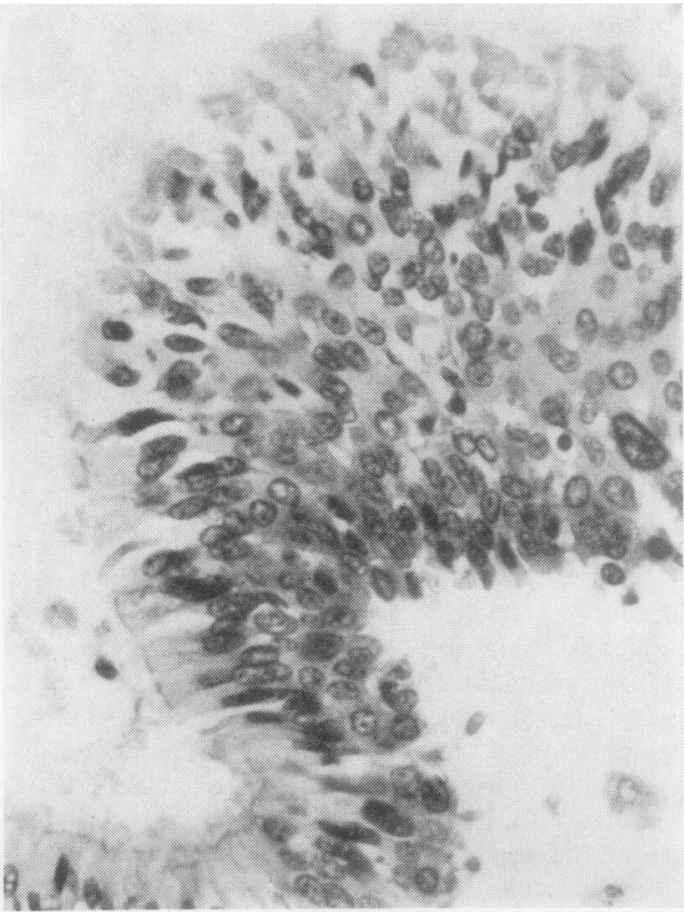

Fig. 6.

Fig. 5 Stratification of sweat gland epithelium beneath a skin vesicle. $H \& E \times 240$.

Fig. 6 Stratification of epithelium in a medium-size bronchus at the periphery of an area of consolidation. $H \& E \times 400$.

Fig. 7 Arteriolar oedema and necrosis in the lung. $H \& E \times 250$. 


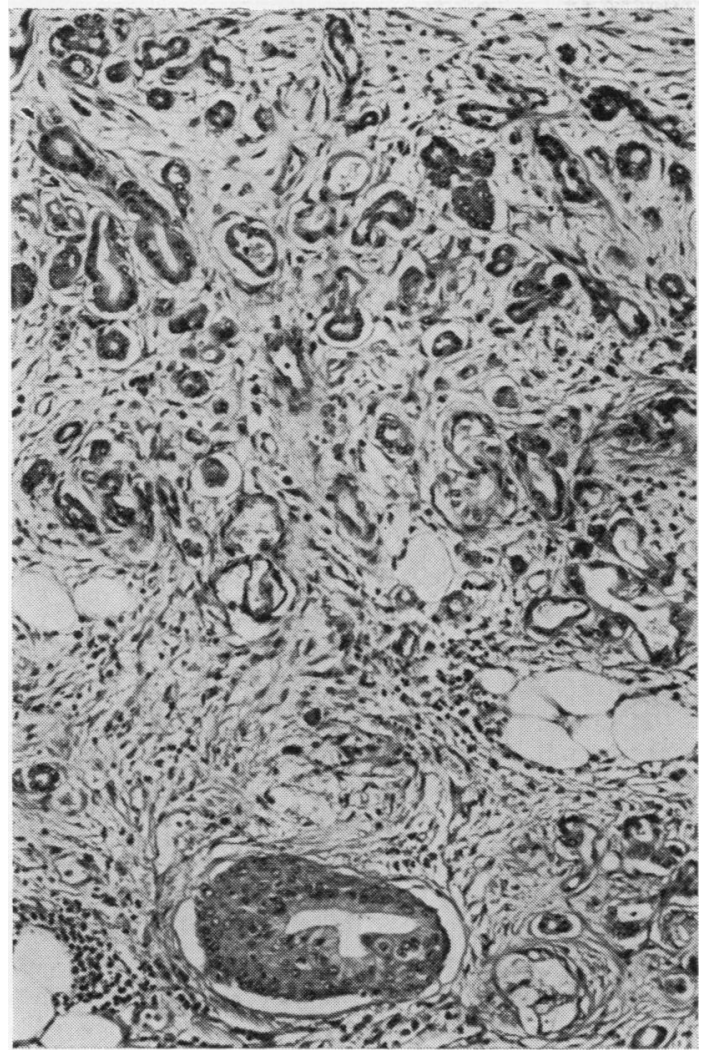

Fig. 8 Area of focal pancreatitis with stratification of the epithelium in one duct. $H \& E \times 100$.

does not appear to have been previously noted. However, intraepidermal proliferation is often present quite early in the development of the vesicles both in vaccinia and in smallpox (Bras, 1952) and has been observed in experimental lesions in animals (Lillie and Armstrong, 1930; Downie and Dumbell, 1947). Since there is no evidence that cells infected by poxviruses are capable of mitotic division, it has been postulated that mitoses occur in uninfected cells when they are stimulated by neighbouring infected cells either by disturbances in their nutritional mechanisms or by breakdown of contact inhibition (Joklik, 1966).

It has been said that the inclusion bodies of vaccinia are basophilic and irregular in outline (B type) and that round eosinophilic inclusions (A type) are rare, occurring only if the strain is from cowpox rather than from variola (Dixon, 1970). However, A type inclusions were present in this case and are also mentioned in seven of 17 cases of human progressive vaccinia in which histological

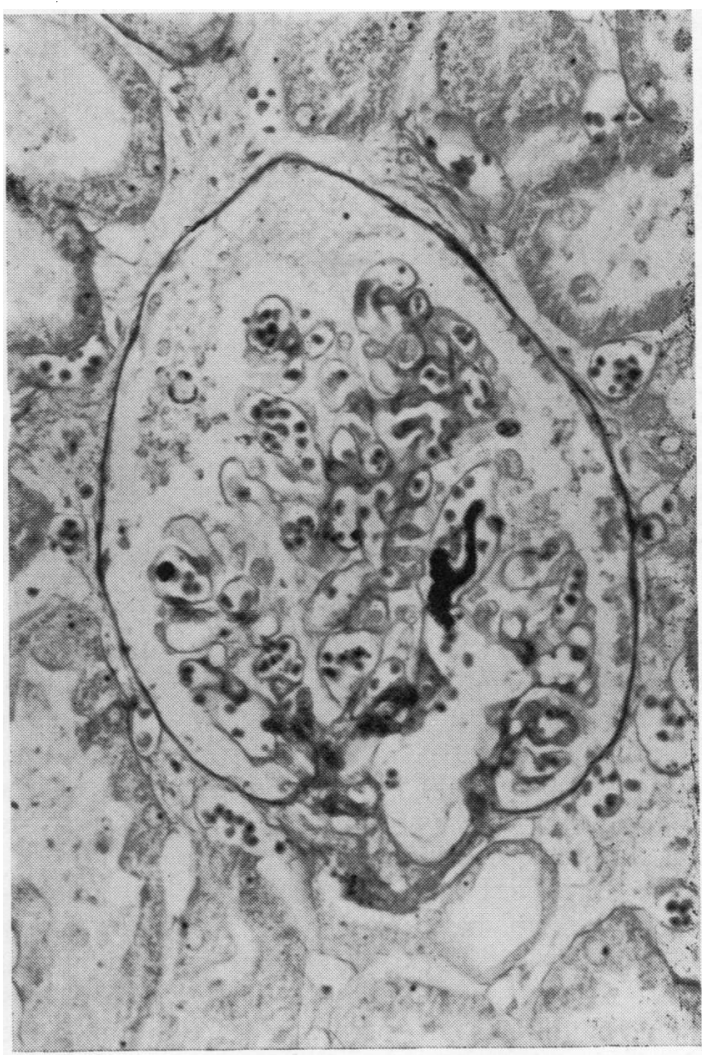

Fig. 9 Delicate fibrin thrombi in a glomerulus. PTAH $\times 375$.

descriptions of the lesions are available (Table). In no case were basophilic inclusions mentioned. This may be due to difficult identification in histological sections or, more probably, a reflection of the fact that the majority of lymphs used for human vaccination are derived from cowpox and not from variola (Horsfall and Tamm, 1965).

\section{VISCERAL LESIONS}

Haematogenous dissemination of the virus is thought to occur in most cases of progressive vaccinia, but only in very severe cases, with new vesicles appearing almost daily, has the virus been isolated from the blood during life (Keidan, MacCarthy, and Haworth, 1953; Sédallian, Badon, Fayolle, and Rouchon, 1957). This is due to the speed with which the relatively large poxviruses are removed from the circulalation by the reticuloendothelial system (Mims, 1964).

A focal necrotizing pneumonitis with little inflammation has been previously noted (Hall, Cunliffe, 


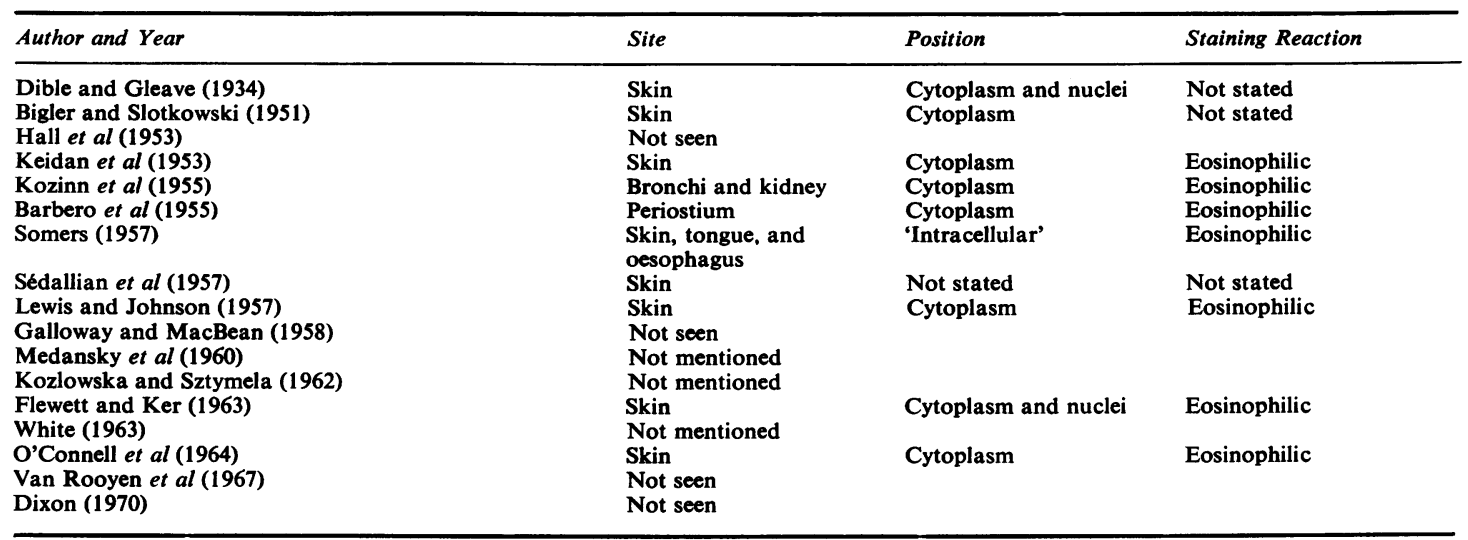

Table Inclusion bodies in human cases of progressive vaccinia

and Dudgeon, 1953; Kozinn, Sigel, and Gorrie, 1955; Flewett and Ker, 1963; Dixon, 1970). In other instances purulent inflammation was also seen (Bigler and Slotkowski, 1951; Lewis and Johnson, 1957; Somers, 1957) but the presence of bacteria in the lesions in two of these cases suggests that this was due to secondary infection.

Proliferative changes of the bronchial or bronchiolar epithelium have also been noted previously (Bigler and Slotkowski, 1951; Lewis and Johnson, 1957; Flewett and Ker, 1963; Dixon, 1970). This change, although not specific, may be useful in the histological diagnosis of the lesions. The proliferation seen in pancreatic ducts in the present case could be interpreted in the same way. We have not found a description of similar pancreatic lesions in the literature, but the pancreas is mentioned in only two instances: areas of focal necrosis were present in one case (Hall et al, 1953) and the organ was macroscopically normal in the other (Shortt, 1933).

There is no previous reference to arteriolar necrosis or thrombosis in human vaccinial lesions. This is surprising, since they are not uncommonly found in smallpox (Bras, 1952) and are often described in experimental vaccinial lesions in rabbits (Ledingham and Barratt, 1929; McIntosh and Scarff, 1929; Lillie and Armstrong, 1930). McIntosh and Scarff thought that vascular lesions were of cardinal importance in the subsequent development of focal necrosis. However, the more detailed descriptions of Lillie and Armstrong show that tissue necrosis usually precedes arteriolar lesions. The electron microscopical observations of Montasir, Rabin, and Phillips (1966) in vaccinial pneumonia of mice confirm that necrosis is essentially due to a cytopathic effect, but they also show that the virus can infect the vascular endothelium. It is therefore possible that ischaemia resulting from vascular lesions may be a contributory factor in the necrosis.

The intravascular fibrin thrombi seen in this case in the lungs, kidneys, pancreas, and spleen suggest disseminated intravascular coagulation, which was never severe enough to produce frank haemorrhagic manifestations. It has been postulated that disseminated intravascular coagulation secondary to endothelial damage by the virus is the cause of the haemorrhagic symptoms which occur in some cases of smallpox, progressive vaccinia, and other viral diseases (McKay, 1965; McKay and Margaretten, 1967). In vaccinia the evidence for this rests mainly on the experimental production of the localized Shwartzman reaction in rabbits with vaccinia virus (Koplik, 1935). A frankly haemorrhagic picture in human progressive vaccinia is rare (Kozlowska and Sztymela, 1962) and ours appears to be the only case in which widespread intravascular thrombi have been seen histologically. However, it remains undecided whether in this case disseminated intravascular coagulation was due to direct endothelial damage by the virus or a result of the anoxia secondary to the terminal state of shock.

It is difficult to evaluate the relative importance of the visceral lesions in causing the death of patients with progressive vaccinia. Bacterial pneumonia and bacterial septicaemia are common terminal complications, but in our case no bacteria were demonstrated in any of the lesions or tissues histologically. It is therefore possible that the vaccinial pneumonia and the intravascular coagulation may have been directly responsible for the otherwise unexplained irreversible shock.

We wish to thank Dr B. Fox for helpful advice in the preparation of this paper and Professor W. St. Clair Symmers for reading the manuscript. We are indebted to Mr F. Humberstone for technical help and 
to the Departments of Photography of Charing Cross Hospital Medical School and The Royal Marsden Hospital for the photographs.

\section{References}

Barbero, G. J., Gray, A., Scott, T. F. M., and Kempe, C. H (1955). Vaccinia gangrenosa treated with hyperimmune vaccinal gamma globulin. Pediatrics, 16, 609-618.

Bigler, J. A., and Slotkowski, E. L. (1951) Smallpox vaccination with prolonged vaccinia. Pediatrics, 7, 24-33.

Bras, G. (1952). The morbid anatomy of smallpox. Docum. med. geog. et trop., 4, 303-351.

Dible, J. H., and Gleave, H. H. (1934). Histological and experimental observations upon generalized vaccinia in man. J. Path. Bact., 38, 29-37.

Dixon, M. F. (1970). Progressive vaccinia complicating lymphosarcoma. J. Path., 100, 53-67.

Downie, A. W., and Dumbell, K. R. (1947). The isolation and cultivation of variola virus on the chorio-allantois of chick embryos. J. Path. Bact., 59, 189-198.

Flewett, T. H., and Ker, F. L. (1963). A case of vaccinia necrosum (or progressive vaccinia) with severe hypogammaglobulinaemia, treated with n-methyl isatin beta-thiosemicarbazone (33T57). J. clin. Path., 16, 271-277.

Galloway, W. H., and MacBean, L. M. (1958). Generalized vaccinia in infancy: a report of four cases. Brit. med. J., 2, 490-492.

Hall, G. F. M., Cunliffe, A. C., and Dudgeon, J. A. (1953). Prolonged generalised vaccinia. J. Path. Bact., 66, 25-38.

Horsfall F. L., Jr., and Tamm, I. (1965). Viral and Rickettsial Infections of Man, 4th ed., p. 953. Pitman, London.

Joklik, W. K. (1966). Poxviruses. Bact. Rev., 30, 33-66.

Keidan, S. E., MacCarthy, K., and Haworth, J. C. (1953). Fatal generalized vaccinia with failure of antibody production and absence of serum gamma globulin. Arch. Dis. Childh., 28, 110-116.

Kempe, C. H. (1960). Studies on smallpox and complications of smallpox vaccination. Pediatrics, 26, 176-189.

Koplik, L. H. (1935). Shwartzman phenomenon in vaccine virus lesions. Amer. J. Path., 11, 842-843.

Kozinn, P. J., Sigel, M., and Gorrie, R. (1955). Progressive vaccinia associated with agamma-globulinemia and defects in immune mechanism. Pediatrics, 16, 600-607.
Kozlowska, J., and Sztymela, L. (1962). Generalized haemorrhagic vaccinia during remission of acute leukaemia. Arch. Dis. Childh., 37, 442-443.

Ledingham, J. C. G., and Barratt, M. M. (1929). On the visceral lesions that may accompany experimental vaccinia in rabbits. Lancet, 2, 515-519.

Lewis, H. M., and Johnson, F. C. (1957). Fatal agammaglobulinemic progressive vaccinia. Arch. Derm. Syph. (Chic.), 75, 837-844.

Lillie, R. D., and Armstrong, C. (1930). The pathology of generalized vaccinia in rabbits. Nat. Inst. Hlth Bull., 156, 1-95.

McIntosh, J., and Scarff, R. W. (1929). The nature of the lesions in generalised vaccinia in rabbits. J. Path. Bact., 32, 551-556.

McKay, D. G. (1965). Disseminated Intravascular Coagulations: an Intermediary Mechanism of Disease, p. 328-329. Harper and Row, New York, Evanston, and London.

McKay, D. G., and Margaretten, W. (1967). Disseminated intravascular coagulation in virus diseases. Arch. intern. Med., 120, 129-151.

Medansky, R. S., Brennan, B. B., and Kennedy, R. P. (1960). Severe vaccination reaction in a leukemic patient. Arch. Derm. Syph. (Chic.), 81, 601-603.

Mims, C. A. (1964). Aspects of the pathogenesis of virus diseases. Bact. Rev., 28, 30-71.

Montasir, M., Rabin, E. R., and Phillips, C. A. (1966). Vaccinia pneumonia in mice: a light and electron microscopic and viral assay study. Amer. J. Path., 48, 877-895.

O'Connell, C. J., Karzon, D. T., Barron, A. L., Plaut, M. E., and Ali, V. M. (1964). Progressive vaccinia with normal antibodies. A case possibly due to deficient cellular immunity. Ann. intern. Med., 60, 282-289.

Sédallian, P., Badon, A., Fayolle, J., and Rouchon, M. (1957). Vaccine généralisée mortelle avec virémie et agammaglobulinémie. Presse méd., 65, 319-321.

Shortt, C. J. (1933). A case of generalized vaccinia. Brit. med. J., 1, 1004-1005.

Somers, K. (1957). Vaccinia gangrenosa and agammaglobulinaemia. Arch. Dis. Childh., 32, 220-225.

Van Rooyen, C. E., Casey, J., Lee, S. H. S., Faulkner, R., and Dincsoy, H. P. (1967). Vaccinia gangrenosa and l-methylisatin3-thio semicarbazone (methisazone). Canad. med. Ass. J., 97, 160-165.

White, C. M. (1963). Vaccinia gangrenosa due to hypogammaglobulinaemia. Lancet, 1, 969-971. 